\title{
Importância da aplicação de critérios morfológicos não-clássicos para o diagnóstico citológico de papilomavírus humano
}

\author{
Application of non-classical morphological criteria in the cytological diagnosis of human papillomavirus
}

unitermos Citologia

HPV

Critérios não-clássicos

\section{Andréa Valderrama Jordão ${ }^{1}$ \\ Léo Sérgio Ruggeri² \\ Giselle Itália Ruggeri Chiucheta ${ }^{3}$ \\ Sérgio Piva ${ }^{4}$ \\ Marcia Edilaine Lopes Consolaro 5}

\section{resumo}

Existe atualmente grande preocupação com a melhoria no diagnóstico citológico de HPV

através da introdução de critérios não-clássicos para o seu diagnóstico, tendo em vista a

elevada freqüência da infecção viral, bem como o seu potencial carcinogênico. O presente

trabalho objetivou uma releitura de 65 casos positivos para HPV por captura híbrida (cujos

critérios inicialmente utilizados foram apenas os clássicos), e a introdução dos critérios não-

clássicos. Os critérios citológicos mais observados foram os não-clássicos, sendo bi ou

multinucleação o mais freqüente, com $n=39(60 \%)$, seguido de halo perinuclear, com $n=$

37 (56,9\%) e disceratose leve e núcleo hipercromático, ambos com $n=32(49,2 \%)$. Para NIC

I predominou a disceratose, com $n=20$ (100\%); para inflamação, disceratose leve, com $n=$

$35(87,5 \%)$ e para Ascus e Agus, halo perinuclear, núcleo hipercromático, células gigantes e

bi ou multinucleação, todos com $n=4$ (100\%). Todos os 20 casos de NIC I, dez dos 40 casos

de inflamação e todos os casos de Ascus $(n=1)$ e Agus $(n=3)$ foram considerados positivos

para HPV com a utilização de critérios não-clássicos, passando a 52,3\% dos casos positivos

pela captura híbrida a apresentarem a infecção viral pela citologia, em detrimento de 23,1\%

só com os critérios clássicos. Um número razoável de amostras diagnosticadas inicialmente

como inflamatórias passaram a apresentar a infecção viral, podendo representar a variedade

subclínica do vírus, para a qual o diagnóstico molecular apresentou-se como melhor

metodologia. A utilização de critérios não-clássicos de HPV pela citologia parece muito

importante para maximizar a eficiência diagnóstica.

\section{abstract}

There is currently a great concern with regard to improvements in the cytological diagnosis of HPV through the introduction of non-classical criteria in its diagnosis. This is important owing to the high frequency of viral infection and its cancerigenous potential. The aim of the research was a reinterpretation of 65 positive HPV cases by hybrid capture. Classical criteria had been used in the first instance and eventually non-classical ones have been applied. The cytological criteria most frequently reported were non-classical. Bi or multinucleation with $n=39(60 \%)$, perinuclear halo with $n=37$ (56.9\%), light dyskeratosis and hyperchromatic nucleus, both with $n=32(49.2 \%)$ were the most frequent. Whereas dyskeratosis was predominant with $n=20(100 \%)$ in NIC I and light dyskeratosis with $n=35(87.5 \%)$ in inflammation, in Ascus and Agus perinuclear halo, hyperchromatic nucleus, giant cells and bi or multinucleation, with $n=4(100 \%)$ each, were predominant. The $20 \mathrm{NICI}$ cases, ten out of the 40 inflammation cases and all Ascus ( $n=1)$ and Agus ( $n=3$ ) cases were HPV positive when non-classical criteria were employed. Hybrid capture revealed $52.3 \%$ of positive cases with viral infection by cytology to the detriment of $23.1 \%$ when classical criteria were used. A considerable number of samples initially diagnosed inflammatory showed viral infection which may represent the virus's subclinical variety. In the latter the molecular diagnosis was the best methodology. The use of HPV non-classical criteria by cytology seems to be important to improve efficiency of diagnosis. 


\section{Introdução}

Foi comprovado atualmente que um fator relevante na gênese do carcinoma cervical está localizado principalmente no genótipo do HPV, favorecido pelos hábitos sexuais da população de risco que pode gerar infecções concomitantes com possível potencial carcinogênico $(4,7)$. O ácido desoxirribonucléico (DNA) específico do HPV pode ser detectado através da reação em cadeia da polimerase (PCR) em $90 \%$ a $95 \%$ dos carcinomas cervicais (11). Tal fato é agravado quando leva-se em consideração que a infecção anogenital causada por HPV é considerada como uma das doenças sexualmente transmissíveis mais comuns e que se apresenta em significante estado emergente (4).

As lesões oriundas de infecção pelo HPV provocam, geralmente, alterações morfológicas características, detectáveis em citologia de raspados cervicovaginais e biópsias. Com isso, são de suma importância os exames rotineiros de detecção precoce de câncer através de esfregaços corados pelo método de Papanicolaou (25). O exame citológico periódico para prevenção do câncer de colo uterino tem sido a melhor estratégia de saúde pública para a detecção de lesões pré-neoplásicas e neoplásicas, sendo desta forma também muito útil na identificação de alterações citomorfológicas relacionadas ao HPV (46).

Historicamente, estas alterações morfológicas em citologia já haviam sido descritas por Papanicolaou em 1933 (33), embora esse autor não reconhecesse nelas a causa de sua expressão. Já em 1956, Koss e Durfee (19) descreveram células com a expressão citopática, utilizando pela primeira vez o termo coilocitose para os halos característicos presentes nas lesões. Em 1960, Ayre (1) aventou pela primeira vez a etiologia viral para a coilocitose, sendo o termo utilizado até hoje.

Atualmente existe grande preocupação em torno da detecção citológica precoce desta infecção e também com a melhoria do diagnóstico citológico, pois em países em desenvolvimento a triagem citológica vem falhando em promover a redução na incidência de câncer cervical, sendo uma das causas a limitação de sensibilidade do método $(20,50)$. Com isto, tem-se estudado a introdução de novos critérios morfológicos, denominados não-clássicos ou secundários para diagnóstico citológico de HPV. O objetivo principal é de que, associados aos clássicos critérios morfológicos, seja ampliada a sensibilidade do método, aproximando-a da obtida em amostras histopatológicas e dos métodos diagnósticos mais sensíveis e específicos, tais como a detecção do DNA viral por captura híbrida ou reação em cadeia da polimerase $(P C R)(8,25)$.

A captura híbrida para detecção de HPV é um exame de biologia molecular altamente sensível capaz de detec$\operatorname{tar} 18$ dos aproximadamente 30 tipos de HPV que mais comumente infectam o trato anogenital. $\mathrm{O}$ grupo $\mathrm{A}$ possui sondas para os HPVs de baixo risco $(6,11,42,43,44)$, e o grupo $B$, sondas para os HPVs de intermediário/alto risco $(16,18,31,33,35,39,45,51,52,56,58,59,68)$. Sua sensibilidade é de $1 \mathrm{pg} / \mathrm{ml}$ de DNA-HPV, equivalente a 0,1 cópia de vírus/célula. Por essa sensibilidade, os estudos têm mostrado estreita relação entre os resultados e a evolução clínica. Os tipos detectados pela metodologia representam $95 \%$ dos vírus que infectam o trato anogenital. Todos os testes de captura híbrida são, ao mesmo tempo, qualitativos e quantitativos (6).

Porém, o grande fator limitante das metodologias moleculares é o elevado custo, tornando-as inviáveis para o exame de grandes populações em programas de saúde governamentais ou até mesmo como procedimento rotineiro em serviços de saúde privados, apesar de alguns autores proporem o teste de DNA para HPV como um complemento para a triagem citológica (49). Estes métodos, para a realidade de países em desenvolvimento, são ainda reservados para casos específicos como: confirmação diagnóstica, resultados conflitantes, genotipagem viral e casos duvidosos à citologia (25).

Dada a importância da citologia oncótica no rastreamento populacional de HPV, a maximização da eficiência morfológica é fundamental para atender às expectativas dos controles periódicos para a prevenção e detecção do HPV, dos cânceres de colo uterino e suas lesões precursoras. Com este intuito, o presente trabalho objetivou uma releitura de esfregaços cervicovaginais de pacientes com diagnóstico de captura híbrida positiva para HPV (cujos critérios citológicos utilizados inicialmente para este vírus foram apenas os clássicos) e a introdução dos critérios nãoclássicos, com o intuito de verificar desta forma a validade da aplicação dos mesmos.

\section{Material e métodos}

\section{Amostras}

Foram selecionados todos os casos positivos de captura híbrida para HPV realizados pelo Laboratório São Camilo de Maringá-PR, no período de $1^{\circ}$ de janeiro de 2000 a $1^{\circ}$ 
de março de 2001, totalizando 65 casos. A captura híbrida foi realizada a pedido médico por motivos clínicos ou laboratoriais. Nestes casos foi levantado o diagnóstico de citologia oncótica cervicovaginal inicial, que levou em consideração apenas critérios citológicos clássicos para diagnóstico de HPV, ou seja, coilocitose e disceratose, segundo o descrito por Koss e Durfee (19). Foram revisados os esfregaços levando em conta também os critérios citológicos não-clássicos para HPV, como descrito adiante.

\section{Coleta e coloração das amostras para Papanicolaou}

As amostras citológicas, quando coletadas no Laboratório São Camilo, foram obtidas através de colheita tríplice sugerida por Wied et al. (47), sendo que o material enviado pelos clínicos variou conforme o critério de coleta adotado. Os esfregaços foram fixados em álcool comercial a $95^{\circ} \mathrm{GL}$ ou com spray de polietilenoglicol. A coloração foi realizada pelo método de Papanicolaou modificado conforme Takahashi (44), utilizando corantes e bálsamo sintético Merck.

Classificações utilizadas para diagnóstico colpocitológico: classificação de Richart de 1967 e o Sistema Bethesda para Citodiagnóstico de 1991 (4, 11).

\section{Critérios morfológicos utilizados}

Os critérios morfológicos utilizados para identificação de HPV foram divididos em critérios clássicos e não-clássicos, como a seguir:

\section{Critérios clássicos}

- Coilocitose: alteração em células escamosas intermediárias maduras contendo um, dois ou mais núcleos discarióticos. Ocorre uma grande cavidade ou área clara que circunda o núcleo proeminente, com bordas bem definidas e a zona periférica amiúde apresenta-se em borrão $(19,28)$;

- disceratose: células espalhadas ou em grupos tridimensionais que demonstram pleomorfismo celular (formas caudadas ou alongadas) e/ou aumento de tamanho e atipia nuclear $(22,28,35,38)$.

\section{Critérios não-clássicos}

- Bi ou multinucleação $(28,30,38)$;

- cariorrexe: trata-se da cromatina condensada perifericamente que permanece como massas agregadas depois do desaparecimento da borda ou limite nuclear (32);
- células fantasmas: são células com clareamento citoplasmático, que têm uma evidente falta de substâncias citoplasmáticas, não coradas, entre o núcleo e a borda celular (38);

- células em fibra: o citoplasma é alongado como uma fibra. Representam a forma mais pronunciada da disceratose e são diferenciadas das células similares encontradas no carcinoma escamoso queratinizante pelo padrão regular da cromatina (38);

- células gigantes: apresentam alterações como binucleação, multinucleação, macronucleose e macrocitose, circundados por halo com borda concêntrica que, aparentemente, separa estes núcleos do citoplasma $(9,27)$;

- células parabasais coilocitóticas: são células pequenas, contendo núcleo maior, fortemente corado e irregular. O citoplasma é anfofílico ou cianofílico e, às vezes, mostra área clara na proximidade do núcleo (29);

- condensação de filamentos: o citoplasma é visto com fissuras ou com aspecto de vidro quebrado e com coloração fraca (38);

- escamas anucleadas: trata-se de células escamosas com citoplasma queratinizado e ausência de núcleo (16);

- grânulos ceratoialinos: são condensações de coloração basofílicas ou eosinofílicas. Freqüentemente as células são anucleadas e, às vezes, todas as substâncias citoplasmáticas estão condensadas em grânulos, formando célula em aspecto de "sarampo" (38);

- halo perinuclear: apresenta-se como uma área clara nítida em volta do núcleo, formando um halo. O núcleo freqüentemente perde detalhes do envelope nuclear e a cromatina pode estar agrupada irregularmente $(28,30,38)$;

- núcleo em borrão: células com citoplasma orangeofílico, às vezes apresentando núcleo aumentado, irregular, hipercromático, podendo ser único ou duplo. A cromatina, na maioria das vezes, aparece em borrão (29);

- núcleo em fibra: consiste em uma distorção do contorno nuclear a partir da configuração arredondada normal ou ovalada do núcleo. A cromatina aparece grumosa e no citoplasma pode aparecer clareamento perinuclear, com numerosos tonofilamentos (40);

- núcleo hipercromático: representado pelo hipercromatismo nuclear e ausência de irregularidades, tanto na cromatina como na membrana nuclear $(28,38)$. 


\section{Captura híbrida}

A coleta foi realizada com kit especial fornecido pela Digene Diagnostics, sendo o material colhido introduzido em tubo com solução conservadora para posterior análise. O sistema de captura híbrida em microplaca foi realizado conforme procedimento descrito pela Digene ${ }^{\circledR}$.

Foram considerados positivos para HPV pela citologia os casos de NIC I, inflamação, Ascus e Agus que apresentaram: um critério clássico associado a quatro ou mais nãoclássicos; dois critérios clássicos associados ou não a critérios não-clássicos e aqueles com quatro ou mais critérios não-clássicos $(7,8,18,46)$.

\section{Resultados}

Os resultados da citologia oncótica inicial dos 65 casos positivos para HPV por captura híbrida demonstraram predominância de casos inflamatórios, com $n=40$ (61,5\%), seguido de NIC I com HPV, $n=15(23,1 \%)$ e assim sucessivamente, conforme Tabela 1.

O critério citológico para HPV mais observado entre os resultados citológicos foi bi ou multinucleação, com $n=39$ (60\%) e como a seguir: halo perinuclear, com $n=37(56,9 \%)$; disceratose leve e núcleo hipercromático, ambos com $n=32$ $(49,2 \%)$; células gigantes e grânulos ceratoialinos, ambos com $n=25$ (38,5\%); núcleo em borrão, com n = 24 (36,9\%); disceratose, com $n=22$ (33,8\%); cariorrexe, com $n=20$ $(30,7 \%)$; coilocitose e células fantasmas, ambos com $n=15$ (23,1\%), como demonstra a Tabela 2.

Para os 20 casos de NIC I, os critérios predominantes foram: disceratose, bi ou multinucleação e núcleo hiper-

\section{Tabela 1 captura híbrida}

Resultado colpocitológico inicial dos 65 casos positivos para HPV por

\begin{tabular}{lcc}
\hline Colpocitologia & $n$ & $\%$ \\
Normal & 1 & 1,5 \\
Inflamatório & 40 & 61,5 \\
Agus & 3 & 4,6 \\
Ascus & 1 & 1,5 \\
NICI com HPV & 15 & 23,1 \\
NICI sem HPV & 5 & 7,7 \\
Total & 65 & 100 \\
\hline
\end{tabular}

NIC I: neoplasia intra-epitelial cervical grau I; Agus: atipias em células glandulares de significado indeterminado; Ascus: atipias em células escamosas de significado indeterminado.

\begin{tabular}{lcc} 
& $\begin{array}{l}\text { Freqüência de critérios citológicos } \\
\text { observados nos } \mathbf{6 5} \text { casos estudados } \\
\text { após a utilização dos critérios não- } \\
\text { clássicos }\end{array}$ & \\
Tabela 2 & Casos & Freqüência \\
Critério & (n) & de casos (\%) \\
morfológico & 15 & 23,1 \\
Coilocitose & 22 & 33,8 \\
Disceratose & 15 & 23,1 \\
Células fantasmas & 2 & 3,1 \\
Células em fibra & 25 & 38,5 \\
Células gigantes & 2 & 3,1 \\
Células parabasais coilocitóticas & 60 \\
Bi ou multinucleação & 39 & 13,8 \\
Coilocitose leve & 9 & 15,4 \\
Condensação em filamentos & 10 & 30,7 \\
Cariorrexe & 20 & 49,2 \\
Disceratose leve & 32 & 6,1 \\
Escamas anucleadas & 4 & 38,5 \\
Grânulos ceratoialinos & 25 & 56,9 \\
Halo perinuclear & 37 & 36,9 \\
Núcleo em borrão & 24 & 10,7 \\
Núcleo em fibra & 7 & 49,2 \\
Núcleo hipercromático & 32 & \\
\hline
\end{tabular}

cromático, com n = 20 (100\%) cada, seguidos de núcleo em borrão com $n=19$ (95\%), células gigantes com $n=18(90 \%)$, halo perinuclear com $n=17$ (85\%) e coilocitose com $n=15$ (75\%), como demonstra a Tabela 3.

Nos 40 casos inflamatórios, predominaram os seguintes critérios: disceratose leve com $n=35(87,5 \%)$, seguido de halo perinuclear com $n=17(42,5 \%)$ e bi ou multinucleação com $n=15(37,5 \%)$, conforme a mesma Tabela 3.

Nos casos de Ascus ( $n=1)$ e Agus ( $n=3)$, os critérios predominantes foram: halo perinuclear, nucleo hipercromático, células gigante e bi ou multinucleação, todos com $n=4(100 \%)$, seguidos de disceratose, com $n=3(75 \%)$, e cariorrexe, grânulos ceratoialinos e núcleo em borrão, com $n=2(50 \%)$, descritos ainda na Tabela 3 .

A Tabela 4 mostra número e tipo de critérios (clássicos ou não-clássicos) observados nos casos de NIC I, inflamação, Ascus e Agus. Para NIC I predominou a presença de dois critérios clássicos associados a cinco ou mais critérios não-clássicos, com $n=14$ (70\%), seguido de um critério clássico associado a cinco ou mais não-clássicos, com $n=4(20 \%)$, dois clássicos e quatro não-clássicos, 


\section{Tabela 3 Critérios citológicos de HPV nos casos de NIC I, inflamação e Ascus e Agus}

\begin{tabular}{lcccccc}
\hline & \multicolumn{2}{c}{ NICI } & \multicolumn{2}{c}{ Inflamação } & \multicolumn{2}{c}{ Ascus e Agus } \\
\cline { 2 - 7 } Critério & $\mathbf{n}$ & $\%$ & $\mathbf{n}$ & $\%$ & $\mathbf{n}$ & $\%$ \\
Coilocitose & 15 & 75 & - & - & - & - \\
Disceratose & 20 & 100 & 4 & 10 & 3 & 75 \\
Células fantasmas & 11 & 55 & 2 & 5 & 1 & 25 \\
Células em fibra & 2 & 10 & - & - & - & - \\
Células gigantes & 18 & 90 & 3 & 7,5 & 4 & 100 \\
Células parabasais coilocitóticas & 2 & 10 & - & - & - & - \\
Bi ou multinucleação & 20 & 100 & 15 & 37,5 & 4 & 100 \\
Coilocitose leve & 4 & 20 & 7 & 17,5 & - & - \\
Condensação em filamentos & 9 & 45 & 1 & 2,5 & - & - \\
Cariorrexe & 14 & 70 & 4 & 10 & 2 & 50 \\
Disceratose leve & - & - & 35 & 87,5 & 1 & 25 \\
Escamas anucleadas & 1 & 5 & 3 & 7,5 & - & - \\
Grânulos ceratoialinos & 12 & 60 & 12 & 30 & 2 & 50 \\
Halo perinuclear & 17 & 85 & 17 & 42,5 & 4 & 100 \\
Núcleo em borrão & 19 & 95 & 4 & 10 & 2 & 50 \\
Núcleo em fibra & 5 & 25 & 1 & 2,5 & - & - \\
Núcleo hipercromático & 20 & 100 & 8 & 20 & 4 & 100 \\
Total de casos & $\mathbf{2 0}$ & - & 40 & - & 4 & - \\
\hline
\end{tabular}

com $n=1$ (5\%) e cinco ou mais não-clássicos, com $n=1$ (5\%). Assim, dos 20 casos de NIC I, todos podem ser considerados como sugestivos da presença viral, levando-se em consideração também os critérios não-clássicos para diagnóstico de HPV (Figura 1).

Nos casos de inflamação, predominou a presença de dois critérios não-clássicos com $n=13(32,5 \%)$, seguido de um não-clássico com $n=9(22,5 \%)$, três não-clássicos com $n=8(20 \%)$, cinco ou mais não-clássicos com $\mathrm{n}=4(10 \%)$, um clássico e cinco ou mais não-clássicos com $\mathrm{n}=4(10 \%)$ e quatro não-clássicos com $\mathrm{n}=2(5 \%)$, como mostra a Tabela 4. Desta forma, dez casos de inflamação podem ser considerados como sugestivos da presença viral, levando-se em consideração também os critérios não-clássicos para diagnóstico de HPV (Figura 1).

Para Ascus e Agus predominou um critério clássico associado a cinco ou mais não-clássicos, com $n=3(75 \%)$,

\section{Tabela 4 Número de critérios morfológicos de HPV para os quadros citológicos}

\begin{tabular}{lcccccccc}
\hline & \multicolumn{3}{c}{ NICI } & \multicolumn{2}{c}{ Inflamação } & \multicolumn{2}{c}{ Ascus e Agus } & \multicolumn{2}{c}{ Normal } \\
Critérios & $\mathbf{n}$ & $\%$ & $\mathbf{n}$ & $\%$ & $\mathbf{n}$ & $\%$ & $\mathbf{n}$ & $\%$ \\
1 clássico e 5 ou mais não-clássicos & 4 & 20 & 4 & 10 & 3 & 75 & - & - \\
2 clássicos e 4 ou mais não-clássicos & 1 & 5 & - & - & - & - & - & - \\
2 clássicos e 5 ou mais não-clássicos & 14 & 70 & - & - & - & - & - & - \\
1 não-clássico & - & - & 9 & 22,5 & - & - & - & - \\
2 não-clássicos & - & - & 13 & 32,5 & - & - & 1 & 100 \\
3 não-clássicos & - & - & 8 & 20 & - & - & - & - \\
4 não-clássicos & - & - & 2 & 5 & - & - & - & - \\
5 ou mais não-clássicos & 1 & 5 & 4 & 10 & 1 & 25 & - & - \\
Total de casos & $\mathbf{2 0}$ & $\mathbf{1 0 0}$ & $\mathbf{4 0}$ & $\mathbf{1 0 0}$ & $\mathbf{4}$ & $\mathbf{1 0 0}$ & $\mathbf{1}$ & $\mathbf{1 0 0}$ \\
\hline
\end{tabular}


seguido de cinco ou mais critérios não-clássicos, $n=1$ (25\%), conforme a mesma Tabela 4. Portanto, os quatro casos entre Ascus e Agus podem ser considerados positivos para a infecção viral, levando-se em consideração também os critérios não-clássicos para diagnóstico de HPV (Figura 1).

Conforme Tabela 4 e Figura 1, se considerados apenas os dois critérios clássicos, a presença de HPV poderia ser sugerida em 15 casos, o que representa $23,1 \%$ daqueles positivos para o vírus por captura híbrida. Levando-se em consideração também os critérios não-clássicos, em 34 casos poderia ser sugerida a presença viral, representando $52,3 \%$ dos casos positivos pela captura híbrida, como representa a Figura 2.

\section{Discussão}

O diagnóstico citológico tem-se mostrado prático para triagem do câncer de colo uterino de grandes populações devido a sua simplicidade, reprodutibilidade, precisão e

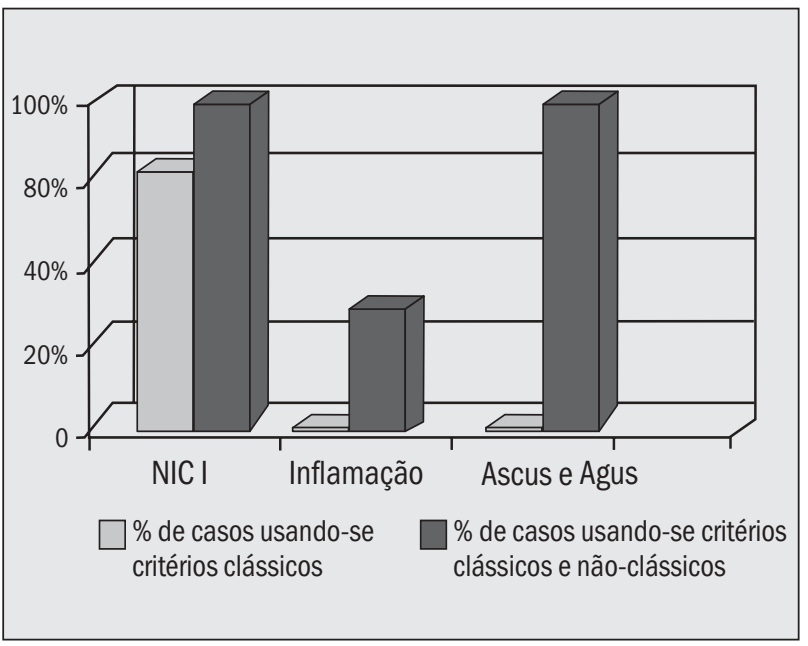

Figura 1 - Freqüência de diagnóstico de HPV para NIC I, inflamação e Ascus e Agus

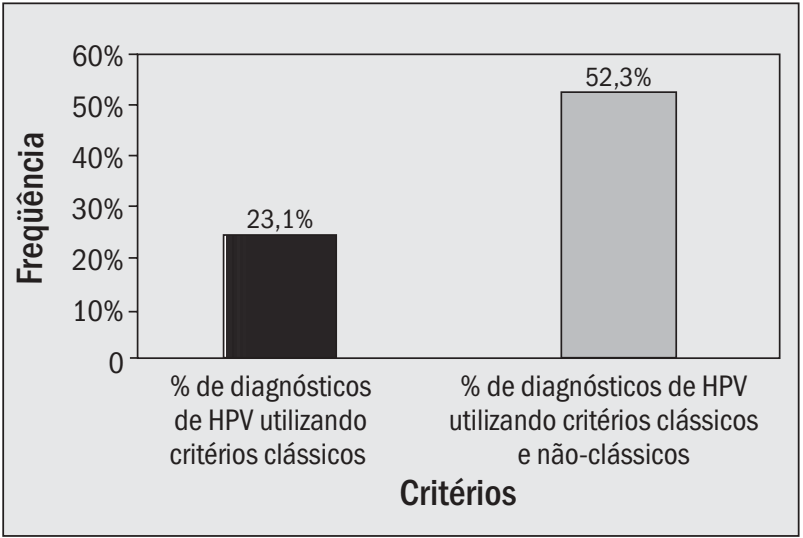

Figura 2 - Freqüência diagnóstica de HPV pela citologia baixo custo, sendo que desde a sua implantação em saúde pública como método de triagem e detecção precoce de neoplasias cervicouterinas, a freqüência de morbidade e de mortalidade decorrentes destes cânceres foram reduzidas significativamente, como pode ser comprovado em países desenvolvidos (11). Porém, o aprimoramento no diagnóstico citológico de infecção cervical por HPV é de grande importância, principalmente devido ao potencial oncogênico que apresentam alguns genótipos de HPV e pela crescente incidência deste agente $(2,13,17,31$, $31,42)$. As dificuldades diagnósticas e o fato de uma parte das infecções por HPV serem assintomáticas e passarem despercebidas pelas pacientes, tornam difíceis as estimativas de prevalência. Acredita-se, no entanto, que aproximadamente $1 / 3$ das mulheres sexualmente ativas abriguem alguma forma de infecção por HPV clinicamente manifesta (26).

A Tabela 2 demonstra que o critério mais observado foi a bi ou multinucleação, com $n=39$, ou seja, presente em $60 \%$ dos casos, seguido de halo perinuclear, com $\mathrm{n}=37$, representando $56,9 \%$ dos casos. Collaço e Pinto (8) apontam em seus resultados a bi ou multinucleação como o critério predominante, que foi visualizado em $91 \%$ dos casos, sendo um resultado superior ao deste trabalho, porém condizente pelo fato de em ambos os trabalhos este ser o critério mais detectado.

Conforme a mesma Tabela 2, a disceratose foi observada em 22 casos, o que representa $33,8 \%$, e a coilocitose em apenas 15 , representando $23,1 \%$ dos casos. Collaço e Pinto (8) relatam que em seu trabalho a disceratose foi observada em $41,3 \%$ dos casos e a coilocitose em $36 \%$, resultados portanto bem mais elevados que os deste trabalho. Apesar da literatura ser unânime em apresentar a coilocitose como critério patognomônico para o diagnóstico de HPV e que exprime a atividade viral, muitos autores destacam, como o demonstrado também nos resultados deste trabalho, que este não é o critério mais freqüentemente encontrado nos esfregaços citológicos (2, $3,14,20,23,38,41,51,52)$.

Destaca-se neste estudo a elevada freqüência de critérios não-clássicos, que são inclusive os mais detectados. Mesmo nos casos de NIC I, a coilocitose apresenta-se apenas como o $4^{\circ}$ critério mais observado, com $n=15$ ou $75 \%$ dos casos. A disceratose, junto com a bi ou multinucleação e núcleo hipercromático, são nestes casos os mais detectados, com $n=20$ ou $100 \%$. A coilocitose não aparece nas citologias inflamatórias nem em Ascus e Agus (Tabela 3). Brown e Fife (5) citam que muitos teci- 
dos infectados, particularmente aqueles com infecção latente, não mostram células coilocitóticas.

Cavaliere et al. (7) descrevem que o achado de quatro ou mais critérios não-clássicos é suficiente para concluir infecção por HPV. Collaço e Pinto (8) preconizam que para confirmar a presença do HPV existe a necessidade de pelo menos dois critérios, sendo que um deles deve ser clássico. Korobowicz et al. (18) relatam que quando observados mais do que três critérios não-clássicos, pode ser relatada a presença do vírus. Neste trabalho, foram considerados sugestivos de HPV os esfregaços que apresentaram um critério clássico associado a quatro ou mais não-clássicos, dois critérios clássicos associados ou não a critérios não-clássicos ou quatro ou mais critérios não-clássicos. Com isto, nos 20 casos de NIC I (na primeira leitura apenas 15), nos dez casos de inflamação (na primeira leitura nenhum) e em um caso de Ascus e três de Agus (na primeira leitura nenhum) pode ser sugerida a presença de HPV, conforme Tabela 4 e Figura 1.

A Figura 2 evidencia que a freqüência diagnóstica de HPV após a inclusão dos critérios não-clássicos passa de $23,1 \%$ para $52,3 \%$, ou seja, eleva-se em $29,2 \%$. Cavalieri et al. (7) descrevem que a utilização de critérios não-clássicos elevou o diagnóstico de HPV em 37,5\%, estando portanto estes resultados e os do presente trabalho bem próximos. Carvalho e Oyakawa (6) também descrevem que a introdução de critérios não-clássicos de HPV aumentam a sensibilidade do exame citológico. Outros autores, em estudos com técnicas biológico-moleculares, entretanto, não conseguiram provar uma relação significativa entre a infecção por HPV e os critérios não-clássicos $(31,48)$, diferindo deste estudo.

Franco (10) relata que com a utilização dos critérios não-clássicos associados aos clássicos na leitura de esfregaços cervicovaginais, a detecção de HPV aumentou sensivelmente, sendo que $80,7 \%$ dos NIC I, $84,6 \%$ dos $\mathrm{NIC} \mathrm{II,} 66,6 \%$ dos NIC III e 52,1\% dos carcinomas cervicais passaram a apresentar estigmas que sugeriam associação com HPV. Pode-se observar que os resultados da Tabela 1, onde não haviam sido utilizados os critérios não-clássicos para HPV e os da Figura 1, onde estes critérios haviam sido aplicados, são bastante diferentes. Desta forma, a concordância entre a citologia oncótica e a captura híbrida elevou-se consideravelmente após a aplicação dos critérios não-clássicos, gerando um aumento na detecção de HPV pela triagem citológica. Este fato é de suma importância no aprimoramento dos serviços prestados, identificando um grupo de pacientes de maior risco para o de- senvolvimento de câncer de colo uterino, como o descrito por Cavalieri et al. (7).

Como a citologia é um método que se baseia nas alterações celulares usualmente associadas a infecção por HPV, às vezes não suficientemente específicas para este agente, casos da infecção viral podem não diferir morfologicamente de reações não-específicas ou alterações inflamatórias $(22,50)$. Deve-se com isto relacionar que um número razoável de casos previamente selecionados como inflamatórios podem ser considerados, aplicando os critérios não-clássicos, como infecção subclínica ou latente por HPV, conforme o descrito por Cavalieri et al. (7) e CarvaIho e Oyakawa (6). Neste trabalho, dez (25\%) dos 40 casos classificados inicialmente como inflamatórios demonstraram critérios principalmente não-clássicos de HPV, suficientes para sugerir o diagnóstico deste vírus. Considerando que os médicos haviam pedido o exame de captura híbrida nestes 40 casos, provavelmente havia suspeita clínica prévia de infecção por HPV e portanto estes dez casos, sugestivos de HPV na segunda leitura, representam possivelmente a variedade subclínica da infecção viral. Vince et al. (50) detectaram o DNA de HPV em $25 \%$ dos casos diagnosticados pela citologia como alterações reativas, coincidindo com o presente trabalho.

Mesmo introduzindo os critérios não-clássicos, a elevação diagnóstica pela citologia em infecções subclínicas ou latentes não é muito representativa. Nos demais 30 casos onde não há características morfológicas para sugerir HPV, a citologia apresenta-se falsamente negativa, pois não existem as características morfológicas virais, que são a base para o diagnóstico citológico $(15,26)$. Trofatter (45) e Koutsky et al. (21) descrevem que, nos casos em que não há manifestações clínicas, sinais morfológicos de HPV podem ser difíceis de detectar. A citologia possui sucesso diagnóstico principalmente nas lesões clinicamente aparentes, conforme o confirmado por Suzuki (42).

Este fato é bastante preocupante, uma vez que pacientes portadoras deste vírus, principalmente de alto potencial carcinogênico, independente de estar em estado clínico, subclínico ou latente, possuem maior probabilidade de desenvolver lesões precursoras e até mesmo cânceres cervicais $(24,34,39,46,50)$. Para estes casos, as metodologias moleculares são as mais indicadas por detectarem o DNA viral, mesmo que em pequenas quantidades, fato este claramente demonstrado no presente trabalho (14). Porém, Trofatter (45) cita que o diagnóstico molecular de casos latentes ou assintomáticos tem seu valor incerto, pois a relevância clínica destes tipos de infecção não está ainda determinada. 


\section{Conclusões}

- Houve elevada freqüência de critérios não-clássicos para diagnóstico de HPV neste trabalho A coilocitose e a disceratose não foram os critérios mais comumente observados, sendo a bi ou mutinucleação e halos perinucleares os mais prevalentes;

- a detecção citológica de HPV mais que dobrou com a utilização de critérios não-clássicos em adição aos clássicos;

- um número razoável de casos previamente diagnosticados como inflamatórios demonstraram a presença do vírus com a utilização dos critérios não-clássicos. Estes podem representar a variedade subclínica da infecção e não seriam anteriormente diagnosticados pela citologia;
- para as modalidades latente e subclínica da infecção por HPV, a melhor metodologia diagnóstica parece ser a molecular, uma vez que a mesma detectou 31 casos da infecção, sendo 30 inflamatórios e um normal, nos quais a citologia não demonstrou a presença viral mesmo com a aplicação dos critérios não-clássicos;

- a utilização de critérios não-clássicos para diagnóstico citológico de HPV parece muito importante se levado em conta o poder carcinogênico de genótipos de HPV bem como a sua crescente incidência;

- este trabalho deve continuar com o objetivo de aumentar a sua amostragem e desta forma estabelecer mais precisamente a importância da introdução dos critérios citológicos não-clássicos para o diagnóstico citológico de HPV.

\section{Referências}

1.Ayre,J.E. Role of the halo cell in cervical carcinogenesis: a virus manifestation of premalignancy? Obstet. Gynecol., 17: 175$82,1960$.

2.Azocar,J. et al. Prevalence of cervical dysplasia and H PV infection according to sexual behavior. Int.J. Cancer, 45: 622-5, 1990.

3. Bibbo, M. \& Moraes Filho, A. Lesões relacionadas à infecção por H PV no trato anogenital. Rio de Janeiro: Revinter, 1998, p. 60-4.

4. Bonfiglio, T.; Erozan, Y.S. Gynecology cytopathology. Philadelphia: Lippincott Raven, 1997, p. 51-72.

5. Brown, D.R. \& Fife, K.H . Human papillo mavirus infections of the genital tract. Med. Clin.North. Am., 74: 1455-85, 1990.

6. Carvalho,J.J.L. \& 0 yakawa, N . I Consenso Brasileiro de H PV. $1^{\text {ạ }}$ ed. São Paulo: BG Cultural, 2000, p. 49-57.

7.C avalieri, M.C . et al. Papilomavírus em saúde pública: importância da aplicação de novos critérios morfológicos para sua deteccção em trato genital feminino. Bol. Inform.Union., 15(59/60):24, 1990.

8. Collaço, L.M. \& Pinto, A.P. Aspectos citológicos na coloração de Papanicolaou da A ssociação de H PV com displasia e carcinoma de colo uterino. J. Bras. Ginec., 104(11/12): 419-21, 1994.

9. De Borges, R.J. et al. Cytologic and ultrastructural findings of a peculiar alteration in cervical cells from patients with human Papillomavirus infections. Acta Cytol., 33(3): 314-8, 1989.

10. Franco, E.L. Epidemio logia do câncer mamário ginecológico. In: A rao, F.S. Tratado de Oncologia Genital e M amária.São Paulo: Roca, 1995, p. 3-16.

11. Gompel, C . \& Koss, L. Citologia ginecológica e suas bases anatomoclínicas. 1a ed. São Paulo: Manole, 1997, p. 79-105.

12. Gross, G.E. \& Barrasso, R. Infecção por papilomavírus humano. Atlas clínico de H PV. Porto Alegre:Artmed, 1999, p.1-18.

13. G upta,J.W .et al. D etection of human Papillomavirus in cervical smears. A comparison of in situ hybridization, immunocytochemistry and cytopathology. Acta Cytol., 31: 387-96, 1987.

14. Jacyntho, C . et al. HPV Infecção genital feminina e masculina. 1a ed. Rio de Janeiro: Revinter, 1996, p. 5-30.

15. Hinchliffe, S.A. et al. Transience of cervical HPV infection in sexually active, young women with normal cervicovaginal cytology. Brit. J. Cancer, 72: 943-5, 1999.

16. Kern, S.B. Significance of anucleated squames in Papanicolaou stained cervicovaginal smears. Acta Cytol., 53(1), 1991.

17. Kochel, H.G .et al. O ccurrence of human papillomavirus D N A types 16 and 18 (HPV-16/18) in cervical smears as compared to cytological findings. Int. J. Gynecol. Obstet., 31 : 145-52, 1990.

18. Korobowicz, E. et al.The diagnostic value of cytomorphological traits in low and high risk type HPV infections. J. Pathol., 48(2): 107-12, 1997.

19.Koss, L.G.\& D urfee,G.R.Unusual patterns of squamous epithelium of the uterine cervix: cytologic and pathologic study of koilocytotic atypia. Ann. NY Acad. Sci, 63: 1245-61, 1956.

20. Koss, L.G.The Papanicolaou test for cervical. A triumph and a tragedy. JAM A, 261: 737-43, 1989.

21. Koutsky, L.A. et al. Epidemiology of genital human papillomavirus infection. Epidemiol. Revist., 10:122-63, 1988.

22. Kurman, R.J. \& Solomon, D. The Bethesda System for reporting cervical vaginal cytologic diagnoses. $\mathrm{N}$ ew York: SpringerVerlag, 1994.

23. Landrac, L. Ko ilocytes: valeur diagnostique. lére. J. Vén. M ars.: 2, 1989.

24. Levi, J.E. HPV: Por que e quando diagnosticar. News Lab, 14:66-72, 1996.

25. Loreto, C .D. et al. Papilomavírus em saúde pública: importância da aplicação de novos critérios morfológicos para sua detecção em trato genital feminino. Bol. Inform. Union, 15 (59/60): 24-39, 1992. 
26. Lörincz, A.T. \& Reid, R.. Clínicas obstétricas e ginecológicas da América do Norte. Papilomavírus humanos.Vol. 3 e 4. Rio de Janeiro: Interlivros, 1996, p. 565-74, 759-86.

27. Luzzatto, R. et al. Multinucleation and abortive cellular division in human papillomavirus infection.Acta Cytol, 34(2):286-7, 1990.

28. M eisels,A \& \& Fortin, R. C ondylomato us of the cervix and vagina: 1) Cytologic patterns. Acta Cytol., 20:505-9, 1976.

29. Meisels, A. et al. Condyloma of the uterine cervix. In: Compendium on diagnostic cytology. 6. ed. Chicago: Illinois, 1988, p. 63-8.

30. N aib, Z.M. \& Masukawa, N . Identification of condyloma acuminata cells in ro utine vaginal smears. Obstet. \& Gynecol., 18(6): 735-8, 1961.

31. N uovo,G.J.et al. H istological correlates of clinically occult human papillomavirus infection of the uterine cervix. Am. J. Surg. Pathol., 12: 198-203, 1988.

32. N uovo, G.J. H uman papillomavirus D N A . In: genital tract lesions histolo gically negative for condylomata. Am. J. Surg. Pathol., 14:643-51, 1990.

33.Papanicolaou, G. Atlas of exfoliative cytology. Cambridge, Massachusetts, Harvard U niversity Press, 1960, p. 18-9 (suppl. 2).

34.Poljak, M. et al. Comparative evaluation of first second generation digene hybrid capture assays of detection of human papillomavirus associated with high or intermediate risk for cervical cancer. J. Clin. M icrob., 37(3): 796-7, 1999.

35. Purola, E. \& Savia, E. Cytology of gynecologic condyloma acuminatum. Acta Cytol., 1:26-31, 1977.

36. Sadoul, G . \& Beuret,T.H . La place du laser dans les lésions du col. La Révue du Practicien., 36: 876, 1986.

37. Schneider, A et al. Sensivity of the cytologic diagnosis of cervical condyloma in comparison with HPV-DNA hybridization studies. Diagn. Cytopathol., 3: 250-3, 1987.

38. Schneider, M.L \& Schneider, V. Citologia ginecológica. Rio de Janeiro: Revinter, 1998. p. 59-61.

39. Shih, L.W .S. et al. Papilomavírus na área metropo litana de São Paulo:aspectos citoló gicos e imunocitoquímicos.Acta Oncol Bras., 8(2): 59-64, Mai/Ago, 1988.
40. Shroyer, K.R. et al. Cytologic diagnosis of human papillomavirus infection:spindled nuclei. Diagn. Cytopathol.,6(3):178-3, 1990.

41. Silva Filho, A.M. \& Longatto Filho, A. Colo uterino \& vagina processos inflamatórios. Rio de Janeiro: Revinter, 2000, p. 123-45.

42.Suzuki, L.E. Eficiência da técnica de Papanicolaou na detecção do papillomavirus humano. D issertação (mestrado) - curso de Saúde Pública - Universidade Estadual de Ponta Grossa. Ponta Grossa, 2000.

43.Syrjänen, K. et al. Factors asso ciated with progression in cervical human papillomavirus (HPV) infections into carcinoma in situ during a long-term prospective follow-up. Brit. J. Obst. Gynaecol., 95: 1096-102, 1988.

44.Takahashi,M .Atlas de Citologia do câncer. $2^{\text {a }}$ ed. São Paulo:Manole, 1982, p. 74-82.

45.Trofatter, K.F. Diagnosis of human papillomavirus genital tract infection.Am. J. Med., 5: 21-7, 1997.

46. Utagawa, M.L. et al. Papillomavirus humano em esfregaços citológicos de mulheres acima de 50 anos: estudo morfológico e de hibridização in situ nas respectivas biópsias. J. Bras. Gin., 107(4): 83-7, 1997.

47.W ied, G .L. et al.Taxono mic intracellular analytic system (TICAS) for cell identification. Acta cytol., 12: 180-204, 1959.

48.W ard,B.E. et al. Cyto logic correlates of cervical pappillomavirus infection. Int. J. Gynecol. Pathol., 9: 297-305, 1990.

49. Van Ballegooijen, $M$. et al. Present evidence on the value of HPV-testing for cervical cancer screening: a model-based exploration of coast-effectiveness. Br. J. Cancer, 76: 651-7, 1997.

50.Vince, A . et al. M olecular detection of human papillomavirus in wo men with minor grade cervical cytolo gy abnormalities. J. Cli. Vir., 20: 91-4, 2001.

51.Yoshinouchi, M. et al. A nalysis by multiplex PCR of the physical status of human papillomavirus type $16 \mathrm{DNA}$ in cervical cancers. J. Clin. M icrob., 37(11): 3514-7, 1999.

52. Zür Hausen, H. Condylomata acuminata and human genital cancer. Cancer Res., 36: 530, 1976.

53. Zür Hausen, H. H uman papillo mavirus and their possible role in squamous cell carcinomas. Current topics. M icrobiol. Immunol., 78: 1, 1977. 